\title{
Relationship between Rapid Strength, Reactive and Strength and Agility in University Sports Students
}

\author{
Felice Di Domenico*, Gaetano Altavilla, Gaetano Raiola \\ Department of Political and Social Studies, University of Salerno, Italy
}

Received November 13, 2021; Revised January 30, 2022; Accepted February 20, 2022

\section{Cite This Paper in the following Citation Styles}

(a): [1] Felice Di Domenico, Gaetano Altavilla, Gaetano Raiola, "Relationship between Rapid Strength, Reactive and Strength and Agility in University Sports Students," International Journal of Human Movement and Sports Sciences, Vol. 10, No. 1, pp. 98 - 103, 2022. DOI: 10.13189/saj.2022.100114.

(b): Felice Di Domenico, Gaetano Altavilla, Gaetano Raiola (2022). Relationship between Rapid Strength, Reactive and Strength and Agility in University Sports Students. International Journal of Human Movement and Sports Sciences, 10(1), 98 - 103. DOI: 10.13189/saj.2022.100114.

Copyright $@ 2022$ by authors, all rights reserved. Authors agree that this article remains permanently open access under the terms of the Creative Commons Attribution License 4.0 International License

\begin{abstract}
Sports training is a complex phenomenon which, to be effective for the planned purposes, must consider all the aspects that make it up. Agility, rapid strength, and reactive strength are factors that contribute, at various levels and in an integrated mood, to the achievement of sporting performance. Often, these aspects are considered separately and not always satisfactory results in the competitive phase, as there is not sufficient knowledge of the relationship between agility and levels of explosive and reactive strength. The aim was to show how these factors (agility, explosive and reactive strength) had interactions with each other that could be exploited in the development and refinement phase. The study was conducted on a sample of 30 students from the University of Salerno who were administered a battery of instrumental tests through the Optojump platform to recruit quantitative data regarding explosive strength, reactive strength, and agility. One way, Anova and post hoc Bonferroni were performed as statistical tools to analyze data. The results showed a significant difference between the groups ( $\mathrm{p}$ $<0.001$ ) regarding the jump height in the tests performed. Bonferroni's test for multiple comparisons found insignificant differences between only two variables: SJ and CMJ. The results may be useful to sports training professionals and athletes to improve sports training programs.
\end{abstract}

Keywords Strength training, Agility, Performance, Quickness, Training Planning

\section{Introduction}

Rapid strength, reactive strength, and agility represent complex psychophysical abilities [1]. They are important characteristics present in most physical and sports actions that presuppose a good level of development of structural and coordinative elements. The development of these characteristics is fundamental for achieving success in both individual and team sports [2]. Rapid strength represents the ability of the neuromuscular system to develop tension in a short time. Explosive strength, a component of rapid force, refers to the acceleration or rate of force development, or the ability of the neuromuscular system to generate high levels of force in a short period [3, 4]. Reactive strength represents the body's ability to achieve the maximum level of concentric force in a very short time after a braking or eccentric movement [5]. Finally, agility is defined as the ability to start, stop and change direction quickly, or the ability to change direction quickly and accurately $[6,7]$ in response to a stimulus [8]. It can take many forms, from simple leg movement actions to full-body movement actions in the opposite direction while running at high speed. Therefore, agility represents a complex feature that involves not only speed but also balances, coordination, and the ability to react to a change in the environment $[9,10,11]$. This ability is an important component in most sports, such as field sports [12, 13]. It is therefore clear that both the explosive and the reactive strength, linked to intramuscular and intermuscular coordination mechanisms, could influence the development and expression of agility.

It is therefore important for performance scholars, 
coaches, and athletes to have more knowledge on the relationships between these characteristics that allow sports actions, to develop adequate training protocols. Training programs do not always guarantee the simultaneous improvement of the three parameters and understanding the possible reasons would lead to the optimization of the programs themselves. Several authors who have conducted studies on youth sports athletes have significantly enriched the knowledge about the improvement of strength and agility. In particular, Sporiš et al. [14] were interested in the correlation between speed, agility, and rapidity in young elite footballers divided by role, showing different values for each role. Horička et al. [15], on the other hand, demonstrated differences in agility levels between different sports specialties. However, research on the correlation between agility and levels of rapid and reactive strength is limited. Many authors [16] agree that the possible cause could lie in the fact that the training methods for these three skills are specific to each of them and therefore not very transferable between them. As agility is a transversal ability related to both structural (muscle strength levels, stiffness, etc.) and coordinative characteristics, its development is linked to the correct identification of exercises and workloads.

However, the possible relationship between these three parameters, rapid strength, reactive strength, and agility, is still not understood. This relationship may change among different target populations, athletes, active, and inactive, and thus should be approached more gradually and carefully. The aim of the following study was a greater comprehension of the variables that most influence the expression of agility and, therefore, finding the relationship between the dependent variable, the agility, and the independent variables, rapid and reactive strength in the population of active students.

\section{Materials and Methods}

\subsection{Participants' Characteristics}

The study took into consideration a sample of 30 students, randomly selected, of the second year of the Bachelor's degree in sports sciences at the University of Salerno. These students were aged between 20 and 25 years $(\mathrm{M} \pm \mathrm{SD}=$ age, $21.97 \pm 1.37$ years old; height, $1.77 \pm$ 0.9 meters, weight, $73.8 \pm 15.03 \mathrm{~kg}$; BMI $23.13 \pm 3.13$ $\mathrm{kg} / \mathrm{m}^{2}$ ). They all played sports at various levels in different disciplines (volleyball, swimming, soccer, martial arts). None of them was a professional athlete. Before undergoing the study, the sample subjects signed informed consent for the processing of personal data.

\subsection{Test Procedures}

A battery of four tests was administered to the samples to enroll data relating to explosive strength, reactive strength, coordination, and agility. The collected raw data were processed and described using specific processing tools. The test battery was administered after an adequate warm-up phase, in the following order:

- Squat Jump test (SJ), to measure explosive strength, which consisted in making a vertical jump starting from a squatting position and keeping the hands on the hips.

- Countermovement jump squat test (CMJ) to measure reactive strength, which consisted of a vertical jump performed immediately after a squat movement. This test was performed in two different ways to enroll two types of data. In the first case, it was performed by placing the hands on the hips which must be held for the entire duration of the test. This test measured the explosive strength referring only to the action of the lower limbs. The second case always involved a vertical jump after a squat phase, but with the difference that the arms were free. In this way, coordinative elements of the arms were added to the reactive action of the lower limbs, which determined, more often than not, an advantage that improved the gesture in terms of results.

- BFS 5 Jump Test - Dot Drill protocol to measure agility. It consisted in completing in the shortest possible time a series of leaps without interruption in various directions. Specifically, the subject entered the area bounded by the bars, placing one foot on circle A and one foot on circle B; at the start beep, the subject quickly jumped with feet together on $C$, then spreading his feet jumped on $\mathrm{D}$ and $\mathrm{E}$ and retraced the path backward until the conclusion beep. The recorded data represented the heights of the jumps. For the BFS test, the average of the jump heights was recorded.

\subsection{Equipment}

The instrumentation used to recruit the above data is represented by an optical sensing system, namely Optojump Microgate. It was of an optical system consisting of a transmit bar and a received bar, each of which was composed of 96 LEDs. The two bars were arranged in parallel to create an area within which the sample units performed tests. The system detected any interruptions in the beam by detecting their duration. Flight and contact times could thus be recorded with an accuracy of $1 / 1000$ th of a second. These data, processed by dedicated software, allowed to obtain a series of parameters related to the performance of the tested subject. The area delimited by the bars consisted of a rectangle measuring $90 \mathrm{~cm} \times 60 \mathrm{~cm}$; inside the rectangle, there were 5 circles of size $10 \mathrm{~cm}$ as in Fig. 1.

\subsection{Statistical Analysis}

Descriptive statistics were used to summarize the data 
by calculating the central tendency and dispersion indices. Before proceeding with the other elaborations, a Shapiro Wilk test was used to verify if the data were normally distributed, to apply parametric tests. A one-way ANOVA was performed to compare the data of groups and to determine if there were significant differences between the means. In addition, a Bonferroni post-hoc test was performed to verify which averages differed from the others. The significance level was fixed at $P<0.05$. All statistical tests were conducted through IBM SPSS.
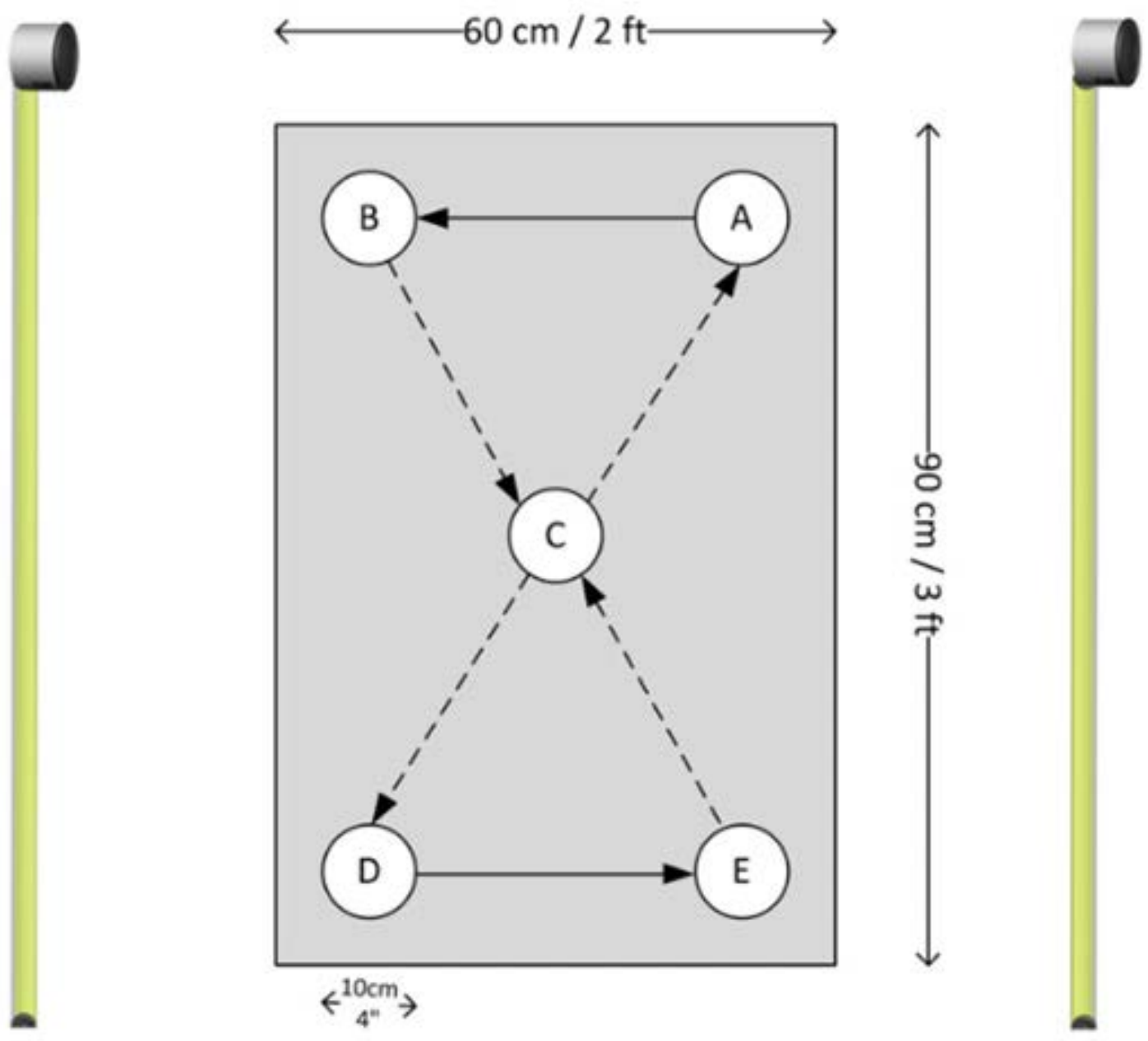

Figure 1. Test area 
Table 1. Test results with Optojump (values in $\mathrm{cm}$ )

\begin{tabular}{|c|c|c|c|c|}
\hline Subjects & $\begin{array}{l}\text { Jump Squat Test } \\
\text { (JS) }\end{array}$ & $\begin{array}{c}\text { Countermovement Jump } \\
\text { Squat (CMJ) }\end{array}$ & $\begin{array}{l}\text { Counter Movement Jump } \\
\text { Squat free arms (CMJ-FA) }\end{array}$ & $\begin{array}{c}\text { BFS } 5 \text { JUMP TEST } \\
\text { (average height jumps) }\end{array}$ \\
\hline 1 & 19.1 & 19.7 & 24.3 & 4,19 \\
\hline 2 & 20.3 & 22.4 & 29.8 & 4,72 \\
\hline 3 & 23.7 & 25.6 & 30 & 6,56 \\
\hline 4 & 32.9 & 32.6 & 39.1 & 5,16 \\
\hline 5 & 15 & 15.7 & 18.2 & 3,30 \\
\hline 6 & 20.6 & 23.4 & 25.2 & 7,29 \\
\hline 7 & 26.2 & 26.7 & 28.2 & 5,53 \\
\hline 8 & 27.3 & 28.2 & 31.8 & 6,82 \\
\hline 9 & 17.9 & 18.3 & 21.8 & 5,30 \\
\hline 10 & 26.9 & 285 & 40 & 4,17 \\
\hline 11 & 23.5 & 24.4 & 32.1 & 2,61 \\
\hline 12 & 33.2 & 35.5 & 41.2 & 4,51 \\
\hline 13 & 32.1 & 33.3 & 41.7 & 4,01 \\
\hline 14 & 16.5 & 17.6 & 22.5 & 3,44 \\
\hline 15 & 30 & 315 & 36 & 3,95 \\
\hline 16 & 19.6 & 20.7 & 27.5 & 4,07 \\
\hline 17 & 25.2 & 27.5 & 36.1 & 2,78 \\
\hline 18 & 21.9 & 23.2 & 33.5 & 2,68 \\
\hline 19 & 25.9 & 26.5 & 27.4 & 7,44 \\
\hline 20 & 18.2 & 20.1 & 31.3 & 4,14 \\
\hline 21 & 33.6 & 35.6 & 45.6 & 2,96 \\
\hline 22 & 26.1 & 25.5 & 22.4 & 6,55 \\
\hline 23 & 25.2 & 27.3 & 26.2 & 6,66 \\
\hline 24 & 26.3 & 27.2 & 27.5 & 4,74 \\
\hline 25 & 24.3 & 27 & 28.8 & 5,08 \\
\hline 26 & 24.1 & 25.6 & 35.1 & 4,21 \\
\hline 27 & 34.5 & 353 & 44.7 & 4,19 \\
\hline 28 & 30.2 & 32.1 & 43.3 & 3,41 \\
\hline 29 & 29.8 & 31.6 & 461 & 5,12 \\
\hline 30 & 28.3 & 30.3 & 32.3 & 4,10 \\
\hline Mean \pm SD & $25.28 \pm 5.35$ & $26.3 \pm 5.44$ & $32.32 \pm 7.69$ & $4.66 \pm 1.37$ \\
\hline
\end{tabular}

\section{Results}

The jump heights relative to each variable were measured. Table 1 showed the data obtained from the four tests administered to the 30 samples. The data referred to jump heights for each trial expressed in centimeters $(\mathrm{cm})$.

The normality of the data was shown through the Shapiro-Wilk test. Table 2 showed the results of the one-way variance analysis conducted with SPSS. These results led to the rejection of the null hypothesis of equality of the means between the groups with a high ratio between variances $(F=147.151)$ and $\mathrm{a} p<0.05$.

Table 2. ANOVA results

\begin{tabular}{c|ccccc}
\hline Source & $\boldsymbol{d} \boldsymbol{f}$ & $\boldsymbol{S S}$ & $\boldsymbol{M S}$ & $\boldsymbol{F}$ & $\boldsymbol{p}$ \\
\hline $\begin{array}{c}\text { Between } \\
\text { groups }\end{array}$ & 3 & 13181,14 & 4393,71 & 147,151 & $<, 001$ \\
Within groups & 116 & 3463,58 & 29,86 & & \\
Total & 119 & 16644,73 & & & \\
\hline
\end{tabular}

Table 3. Post-hoc Bonferroni

\begin{tabular}{ccc}
\hline (I) TEST & (J) TEST & Sig. \\
SJ & CMJ & 1,000 \\
& CMJ-FA & $<, 001$ \\
& BFS 5 & $<, 001$ \\
CMJ & SJ & 1,000 \\
& CMJ-FA & $<, 001$ \\
& BFS 5 & $<, 001$ \\
CMJ-FA & SJ & $<, 001$ \\
& CMJ & $<, 001$ \\
& BFS 5 & $<, 001$ \\
BFS 5 & SJ & $<, 001$ \\
& CMJ & $<, 001$ \\
& CMJ-FA & $<, 001$ \\
\hline
\end{tabular}

The analysis of variance, however, did not allow conclusions to be reached about which and how many 
groups differed from each other. Therefore, the multiple comparison procedure with the Bonferroni test was performed to see which pairs of means were actually and significantly different. Table 3 showed the results: there was a significant difference between the BFS test and the other three tests, while there was no significant difference between the SJ test and the CMJ test.

\section{Discussion}

The purpose of the study was to identify the difference between the results of the four tests and to verify if this difference had a statistical significance. The results showed a significant difference between the mean results of almost all tests. Only the Squat jump test and Counter Movement Jump Squat used to test explosive strength and reactive strength, respectively, showed no significant difference. These results may suggest useful insights for programming various physical and sports skills. Agility, being a transversal ability, should include planning for its transversal improvement, where both structural and coordinative aspects (strength, speed, reactivity, coordination, perception) are considered in the right dose. Many studies [17, 18, 19] confirmed that combined and integrated training in different contexts produced greater effects on agility improvement than single-mode training with little variable environments. Markovic et al., for example, showed that sprint training improves the strength, power, and agility of the leg extensors [20]. The programs for the development of explosiveness, a component of a rapid force and reactive force, according to the results of the study, follow parallel paths, each with its characteristics. These expressions of force have different characteristics, and therefore, different strategies are used for their development. Exercises that provide acceleration are used for explosive strength to stress maximum force development in a short time. One strategy is represented by the improvement of the rate of force production [21] with neural adaptations that allow a greater speed of recruitment of motor units, especially those with rapid contraction [22]. Reactive strength training exploits the stretch-shortening cycle (SSC) that allows the accumulation of elastic energy within the muscle and its elastic components during a braking movement that allows a subsequent greater concentric contraction as long as this occurs in a short time $[23,24]$.

\section{Conclusions}

The study showed significant differences in almost all parameters, except for Jump Squat and Counter Movement Jump Squat. The study gave useful ideas for application in the physical and sports fields for better training planning and programming of training. In planning and programming training, the professional performance must consider the greatest number of variables that can affect the training result to improve performance and limit injuries. This study can represent an aid for the choice of exercises and methodologies to be introduced in a program within athletic training.

\section{Conflict of Interest}

There are no conflicts of interest.

\section{REFERENCES}

[1] Verkhoshansky YV., "Quickness and Velocity in Sports Movements,” New Studies in Athletics, vol. 11, pp. 29-37, 1996.

[2] Rienzi E., Drust B., Reilly T., Carter JEL., Martin A., "Investigation of anthropometric and work-rate profiles of elite South American international soccer players,” J Sports Med Phys Fitness, vol. 20, no. 2, pp. 162, 2000

[3] Weineck J., “L’allenamento ottimale,” Perugia, Calzetti e Mariucci, 2009.

[4] Stone MH., "Position Statement. Literature review: Explosive Exercises and Training," NSCA Journal, vol. 15, no. 3, pp. 7-14, 1993.

[5] Schmidtbleicher D., Gollhofer A., Einflussgrößen des reaktiven Bewegungsverhalten und deren Bedeutung für die Sportpraxis; Grundlagen des Maximal-und Schnellkrafttrainings," Schriftenreihe des Bundesinstituts für Sportwissenschaft, vol. 56, pp. 271-281, 1985.

[6] Brown LE., Ferrigno VA., "Training for speed, agility, and quickness,” 2nd Edition, Human Kinetics, Champaign, 2005.

[7] Zemkovà E., Hamar D., “Agility performance in athletes of different sport specializations,” Acta Gymnica, vol. 44, no. 3, pp. 133-140, 2014.

[8] Sheppard JM., Young WB., "Agility literature review: classifications, training, and testing,” J. Sports Sci, vol. 24, no. 9, pp. 919-932, 2006.

[9] Měkota K., "Definice a struktura motorických schopností (novější poznatky a střety názorů),” In: Česká kinantropologie, vol. 4, no. 1, pp. 59-69, 2000.

[10] Plisk SS., Speed, agility and speed endurance development. Essentials of strength training and conditioning. Baechle TR, Earle RW, editors. Human Kinetics, pp. 427-470, 2000.

[11] Young WB., James R., Montgomery R., "Is muscle power related to running speed with changes of direction?," J Sports Med Phys Fitness, vol. 42, no. 3, pp. 282-288, 2002.

[12] Bloomfield J., Polman R., O'Donoghue P., "Deceleration movements performed during FA Premier League soccer matches,” J Sports Sci Med, vol. 6, pp. 63-70, 2007.

[13] Green BS., Blake C., Caulfield BM., "Comparison of cutting technique performance in rugby union players,” J Strength Cond Res, vol. 25, pp. 2668-2680, 2011. 
[14] Sporiš G., Milanovi Z., Trajkovi N., Joksimovi A., "Correlation between speed, agility and quickness (saq) in elite young soccer players” Acta Kinesiol, vol. 5, no.2, pp. 36-41, 2011.

[15] Horička P., Hianik J., Šimonek J., “The Relationship between Speed Factors and Agility in Sport Games”, Journal of Human Sport \& Exercise, vol. 9, no. 1, pp. 49-50, 2014.

[16] Young WB., Mcdowell MH., Scarlett BJ., "Specificity of Sprint and Agility Training Methods,” Journal of Strength and Conditioning Research, vol. 15, no. 3, 2001.

[17] Makhlouf I., Chaouachi A., Chaouachi M., Ben Othman A., Granacher U., Behm DG., "Combination of Agility and Plyometric Training Provides Similar Training Benefits as Combined Balance and Plyometric Training in Young Soccer Players,” Front Physiol, vol. 13, no. 9, pp. 1611, 2018.

[18] Holmberg P., “Agility Training for Experienced Athletes: A Dynamical Systems Approach,” Strength and Conditioning Journal, vol. 3, no. 5, pp. 73-78, 2009.

[19] Nur Cholis Majid, Fauzi. The Effect of Sprint Training on Vertical Jump Height of Female Youth Volleyball Players. International Journal of Human Movement and Sports
Sciences, 9(2), 334-339, 2021. DOI: 10.13189/saj.2021.090222.

[20] Markovic G., Jukic I., Milanovic D., Metikos D., "Effects of sprint and plyometric training on muscle function and athletic performance," Journal of Strength and Conditioning Research, vol. 21, no. 2, pp. 543-549. DOI: 10.1519/R-19535.1

[21] McLellan CP., Lovell DI., Gass GC., "The role of rate of force development on vertical jump performance," The Journal of Strength \& Conditioning Research, vol. 25, no. 2, pp. 379-385, 2011.

[22] Tillin NA., Folland JP., "Maximal and explosive strength training elicit distinct neuromuscular adaptations, specific to the training stimulus,” Eur J Appl Physiol, vol. 114, no. 2, pp. 365-374, 2014.

[23] Vaczi M., Racz L., Hortobagyi T., Tihanyi J., "Dynamic contractility and efficiency impairments in stretch-shortening cycle are stretch-load-dependent after training-induced muscle damage,” J Strength Cond Res, vol. 27, no. 8, pp. 2171-2179, 2013.

[24] Komi PV., Gollhofer A., "Stretch reflexes can have an important role in force enhancement during SSC exercise," J Apple Biomech, vol. 13, no. 4, pp. 451-460, 1997. 